1978

\title{
Papers in Applied Archaeology
}

Joel Gunn

Center for Archaeological Research

Follow this and additional works at: https://scholarworks.sfasu.edu/ita

Part of the American Material Culture Commons, Archaeological Anthropology Commons, Environmental Studies Commons, Other American Studies Commons, Other Arts and Humanities Commons, Other History of Art, Architecture, and Archaeology Commons, and the United States History Commons

Tell us how this article helped you.

This Article is brought to you for free and open access by the Center for Regional Heritage Research at SFA ScholarWorks. It has been accepted for inclusion in Index of Texas Archaeology: Open Access Gray Literature from the Lone Star State by an authorized editor of SFA ScholarWorks. For more information, please contact cdsscholarworks@sfasu.edu. 


\section{Papers in Applied Archaeology}

Creative Commons License

(c) () () (9)

This work is licensed under a Creative Commons Attribution-NonCommercial 4.0 International License 
PAPERS IN APPLIED ARCHAEOLOGY

edited

by

Joe1 Gunn

Center for Archaeological Research

The University of Texas at San Antonio

1978 
TABLE OF CONTENTS

Page

ACKNOWLEDGMENTS

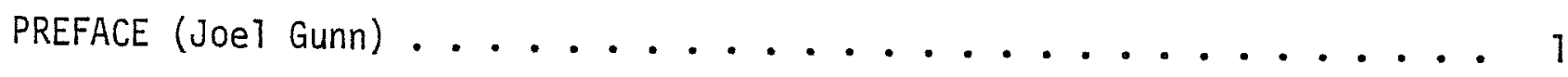

I. APPLIED AND BASIC RESEARCH IN ARCHAEOLOGY: IMPLICATIONS FOR

ARCHAEOLOGY AS PART OF THE SCIENTIFIC COMMUNITY (W. J. Mayer-Oakes) . . 4

Introduction ..................... 4

Status of the "Art" of Applied Anthropology .........4 4

Contract Archaeology is a Business: Applied Archaeology .... 5

Academic Archaeology is (the New) Traditional Archaeology ... 5

The CRI Experience . . . . . . . . . . . 7

Basic Research Implications .............. 7

The New Contract Process ............... 8

Review of Research Types................ 9

A Potential Problem .................... 11

Summary and Conclusions ....................... 11

References ........................... 12

II. ARCHAEOLOGY, A MATTER OF PUBLIC INTEREST (E. Mott Davis). . . . . 15

The Romantic Interest in Archaeology . . . . . . . . 15

The Esthetic Interest in Archaeological Materials . . . . 16

The Interest in the Nature of the Human Community . . . . . 16

The Interest in Social Roots ............ 17

The Interest in Archaeology as a Technical Hobby . . . . . . 17

Conclusion ...................... 17

III. ARCHAEOLOGY AND TROUBLED TIMES: CULTURES ASTRIDE SHIFTING CLIMATES

AND SLIDING RESOURCES (Joel Gunn) . . . . . . . . . . 19

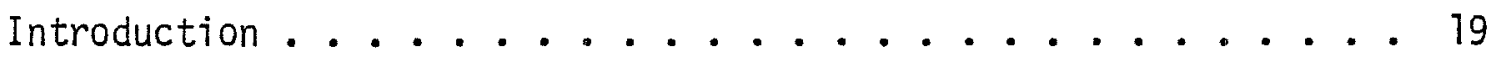


Page

Models of Climatic Change ............ 20

Models of Cultural Adaptation ............. 21

Conclusions ....................... 22

References ..................... 22

IV. ARCHAEOLOGY: SCIENCE AND ENGINEERING (Les Davis) . . . . . . 24

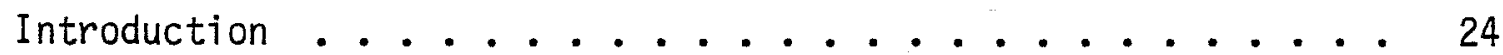

Archaeological Engineering ............ 24

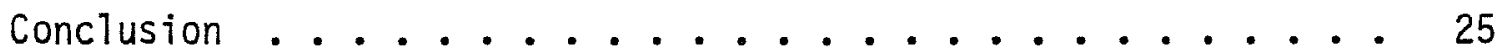

References ................ 26

V. RESOURCE MANAGEMENT: THE FUTURE OF THE PAST (A1ton K. Briggs) . . . 27

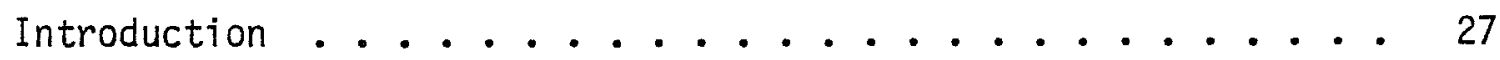

The Problem: Dwindling Archaeological Resources . . . . . 27

First Step Solution: Public Law . . . . . . . . . 27

Second Step Solution: A Conservation Ethic . . . . . . . 28

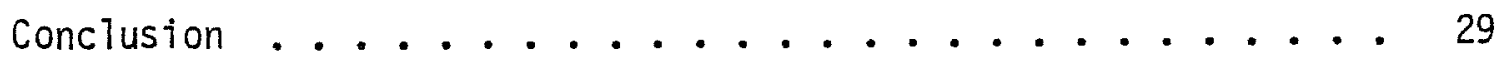




\section{ACKNOWLEDGMENTS}

The authors of the various papers in this volume extend their appreciation to Dr. Thomas R. Hester, Direcior, Center for Archaeological Research, The University of Texas at San Antonio, for facilitating the publication of the papers presented at the Symposium on Applied Archaeology at the 1978 Cibola Anthropological Association Conference. Also, the editor thanks his fellow participants for their prompt and enthusiastic submission of papers for publication. 


\section{PREFACE}

Joel Gunn

Whether or not archaeology has an applied aspect is something of a conversation stopper. Some archaeologists hold that it has no apparent practical value, and that it in fact justifies its existence out of human interest in the past. Some of this interest centers around scholarly activity. Closer to the public sector, recognition that heritage and recreation are closely associated has recently resulted in some major reorganization of U.S. government bureaucracies (see Briggs, this volume). In other parts of the world, such as France and Mexico, providing archaeological entertainment for the public has long been the staple of certain government service organizations. To the extent that the public interest and conscience are served, it is legitimate to think of archaeology as a practical undertaking.

The papers presented in this volume are concerned not only with the public interest aspect of archaeology but also with alternative and direct practical benefits. The thinking presented was occasioned by a massive increase in public expenditure for archaeological investigation. The papers certainly do not exhaust the topic, but we feel they do provide a fairly well rounded view of practical archaeology in the state of Texas. Fritz (1973) has provided the 1 iterature with a well founded discussion of the relevance of archaeology. We realize that conditions and orientations elsewhere differ, and a more broadly based symposium is being organized for the 1978 American Anthropological Association meeting.

The papers printed herein were originally presented at the annual Ciboia Anthropological Association Conference in Austin on March 11, 1978. Five papers were read. The first two, by William J. Mayer-0akes and E. Mott Davis, are concerned with the public foundations and future of archaeology. The last three papers are more concerned with the efficient and beneficial application of public funds to archaeological problems. They were presented by Joel Gunn, Les Davis and Alton Briggs. The session was chaired by Joel Gunn.

W. J. Mayer-Oakes' paper points out that archaeology has no obvious applied tradition such as that attributed to physical anthropologists who design seats for aircraft, or cultural anthropologists who work with international development projects. Even so, public policy, most of which archaeologists had little say in designing, has called for a tremendous effort on the part of the profession to preserve the nation's prehistoric and historic heritage. In order to cope with the problem, archaeologists must radically rethink their position in the scientific community and their modes of operation. Of special importance is the need to insure that public monies designated for archaeological work are managed in a businesslike manner and that they serve public archaeological purposes rather than the purposes of individuals. Without immediate conscious effort, neither end will be realized.

As Mott Davis indicates, archaeology is very high on the public's list of topics of general interest. It is suggested that this interest stems from five sources. The first two, romantic notions and esthetics, are a mixed blessing from the point of view of archaeology since they often foster destructive acts 
toward the archaeological record. The last three, interest in human variety, concern for social roots and interest in archaeology as a technical avocation, encourage responsible attitudes toward monuments of the past and therefore should be actively supported by professionals.

Joel Gunn's presentation suggests that applications of archaeological knowledge lie mostly in the realm of basic research and knowledge about human origins. Recent circumstances, however, indicate that archaeologists can play a direct role in the research and development phases of economic planning in modern societies. Apparent drastic climatic changes are placing the public in dire need of knowledge concerning projected climatic trends and alternative solutions to coping with abnormal conditions. The long term paleoclimatic and cultural data sets controlled by archaeologists provide as clear a potential solution to the problem as any available. The author is conducting research on south Texas climate and cultural adaptations to that end.

Les Davis observes that the archaeologist who acts in the roles of both scientist and engineer is being wasteful. The growing archaeological industry should seriously consider developing archaeological engineers by offering degree programs in the subject. Archaeologists should develop a "Handbook of Applied Archaeological Techniques" containing recommended practices for shoring excavations, wiring sites for electricity, etc. Such a handbook would add to the safety and efficiency of archaeology.

Alton Briggs' presentation points out that archaeology as a discipline is responsible for the management of a perpetually and irreversibly dwindling resource, the archaeological record. The strategy at present is to balance the loss by preserving as full a range of archaeological sites as possible. In fact, there is a wave of public interest in preserving evidence of the past, and private individuals have more than once expressed criticism of professional archaeologists' inability to discover and preserve sites. Briggs suggests that, in addition to pub7ic law, a conservation ethic is needed to guide resource management objectives.

Persons invited to the symposium were drawn from a wide range of archaeological involvements. William J. Mayer-Oakes is head of the Cultural Resources Institute at Texas Tech University, Lubbock, Texas. He has been involved for some time in promoting awareness of imminent changes in the future of archaeology, political action favorable to archaeological purposes and public awareness of archaeological problems.

Mott Davis has an enduring interest in public awareness of archaeology, stemming from many years' involvement in archaeological film making. He is Professor of Anthropology at the University of Texas at Austin.

Joel Gunn was led to an interest in practical applications of archaeology when paleoclimatic research required the analysis of several modern weather and climate data sets. He is at The University of Texas at San Antonio.

Les Davis is the president-elect of the Texas Archeological Society and is a lifelong amateur archaeologist. He is employed as an engineer by the U.S. government, testing missiles. 
Alton Briggs is the Director of Cultural Resource Management with the Texas Historical Commission. He is active in developing a program to direct the future use and preservation of cultural resources in the state for public and professional benefit.

\section{REFERENCE}

Fritz, John M.

1973 Relevance, Archeology and Subsistence Theory, In: Research and Theory in Current Archaeology :59-82. C. Redman, ed., Wiley, New York. 


\section{APPLIED AND BASIC RESEARCH IN ARCHAEOLOGY: \\ IMPLICATIONS FOR ARCHAEOLOGY AS PART OF THE SCIENTIFIC COMHUNITY \\ W. J. Mayer-Oakes}

\section{Introduction}

The idea for this paper (and in part for this symposium) came from the process of writing a preliminary paper in October 1977 on the topic of "Bureaucrats or Scholars" (Mayer-0akes 1977). As that interest has been further developed for a revised paper to be presented at the 1978 Society for American Archaeology meeting, it became clear that the facts of the current strength and amount of "applied" archaeology (contract work) were less in need of emphas is than the implications of these facts. Some of the implications are for actions that the profession of archaeology needs to take in the general context of science and scholarship. Other implications are for internal review and revision of long held, often implicit, ideas and attitudes about what archeology is, what it does and what it can do. Both of these sets of implications will be explored in a preliminary way in this paper.

\section{Status of the "Art" of Applied Anthropology}

In the area of socio-cultural anthropology, the concepts and practices of applying research and fundamental approaches for "practical" ends are in a state of dynamic change. Some of this is documented in the November-December 1977 issue of Revieus in Anthropology. At the March 1978 Cibola Association annual meeting, the distinguished speaker Laura Nader outlined strikingly the potential for this direction of research movement for anthropology. She also demonstrated her own pioneering role in the "ethnography of work" kinds of research activities. Both of these sets of new kinds of cultural anthropology can build on a significant and explicit tradition of "applied anthropology, "although I foresee strong divergences from this tradition.

A similar explicit tradition of applied work exists in the subfield of physical anthropology. I am thinking here of the specific anatomical design applications for military use and the long established links with Air Force research. While I am not aware of as strong a background of explicit applied activities in linguistics, certainly the language teaching activities of both public and private schools have drawn on basic research done by linguists.

In archaeology, in many ways the most mundane and "down to earth" part of anthropology, there is little to point to as a background or tradition of "applied" work. In fact, the variety of things done for many years as contract or salvage archaeology can be considered applications of archaeology. But, we have not thought of them this way, nor have we developed an explicit body of professional applied practioners--until recently. My suggestion is that current contract work in archaeology is in fact "applied" archaeology (Mayer-Oakes 1977, 1978a). Accepting this point of view, comparisons with other scientific fields and their developments can open up a new universe of potential growth for archaeology. 
Hester Davis (1976) has recently also raised a voice seeking recognition of the "applied" nature of contract archaeology. She points out, in addition, that much of this development of contract-based, applied archaeology is a result of compliance with public policy (laws and regulations) which the profession of archaeology did not help frame, e.g., the Historic Preservation and National Environmental Protection Agency (NEPA). Although these bases for contract archaeology date back to the mid-and late 1960 s after the promulgation of Executive Order 11593 in 1971 and the passing of the Moss-Bennett Bi11 in 1974, there has been a tremendous acceleration in both contract archaeology and the employment of archaeologists in public, primarily federal, agencies. Both Davis and I have contended that a new kind of archaeology has already been created and is well established, more or less under our very noses (and feet!). The profession of archaeology has only in part attempted to cope with this by holding cultural resource management conferences (Lipe and Lindsay 1974) and establishing state archaeological councils (e.g., the New Mexico Archaeological Council and the Council for Texas Archaeology) and a professional association, the Society of Professional Archaeologists. My point here is to emphasize the already accomplished or extant nature of this new field of applied archaeology. Later in the paper I attempt to define it in some detail.

Two facts which help to underscore the extant nature of the field are as follows:

(1) The Bureau of Land Management is now the largest single employer of archaeologists in the U.S. (and probably in the world)--there are 170 BLM archaeologists (R. Morrison, personal communication);

(2) The only market analysis yet done for contract archaeology (Fitting 1978b) concludes that the annual size of this market is no less than $\$ 50,000,000$. This is about the size of the budget for a small regional airline in the U.S. (e.g., Texas International in 1973).

The heading for this section seems an inevitable conclusion--contract archaeology is a significant business phenomenon, and if there is anything we can ever call applied archaeology, this is it!

\section{Academic Archaeology is (the New) Traditional Archaeology}

The current dilemma or "scholar's lament" characteristic of the traditional academic archaeologist is 177 ustrated by a recent dialog published in the Pennsylvania Archeologist (Kinsey 1977, Fitting 1978a). The dialog can be viewed as between Kinsey, the "old" or traditional archaeologist, and Fitting, the "new" or contract archaeologist, doing applied archaeology in a corporate or business setting.

In his statement of the academician's dilemma, Kinsey conments and in a sense complains about the unrealistic time pressures of contract work. The time schedules are, in fact, not at all related to the traditional academic time 
framework for professors and students. Other points of concern to kinsey include a rather undecided or contradictory attitude toward doing archaeology for monetary profit, the whole new area of professional ethics in a businesslike competitive context and the concern for quality of archaeological work done under contract conditions.

Specifically responding to Kinsey's lament, Fitting presents the rationale for, and a personal view of, the new realm of business archaeology. Using a framework of "orientation" to archaeology, he defines three distinguishable but complementary views: problem orientation, resource orientation and client orientation.

The view which Fitting takes is the latter; he is a corporate archaeologist, hired by his company (Commonwealth Associates) to serve the interests of clients requiring professional archaeological services, in much the same way that a corporate context can provide professional legal, medical or scientific services for clients. The ultimate basis and reason for such a corporation, of course, is profit or financial gain.

As I understand these three orientations, they do provide us a solid analytical basis for distinguishing and clarifying legitimately different kinds of archae0logy. Elsewhere (Mayer-0akes 1978b,c) I have presented this viewpoint in more detail. For this paper I simpiy say that a "problem" orientation is most characteristic and perhaps most appropriate for academic archaeology and what we could call "pure" research. The "resource" orientation is clearly the bas is for all public-supported archaeology stemming from public policy (i.e., in response to law and regulation). This is the area of cultural resource management activities and could be either basic or applied research. The "client" orientation is the narrowest focus and only on the rarest occasion would we expect business clients (coal companies, oil exploration companies, housing developers) to finance basic or pure research in archaeology. They are interested in "clearances" and any other necessary compliance (usually at minimal cost) with the pertinent law and regulation.

How Kinsey or others will react to this response from Fitting, I am not sure. I see two possible responses as likely. One is rejection of participation in this new and different kind of archaeology, which is what many academic archaeologists are currently doing. The pejorative connotations of "applied" science seem paramount in supporting this course of action. In this reaction, archaeologists are responding to the "real world" cutside of academia in a way similar to that adopted by many other academic scientists. There is an attempt to keep academic interests and research "pure" or uncontaminated by practical interests or applications. The second kind of reaction is in fact a range of reactions-from partial to full or enthusiastic immersion in the kind of archaeology that contract work is creating. Fitting has recently described some of the salient features of this new field (1977, 1978b). His approach has been to abandon the "traditional" academic framework for scholarship (whatever that is) and to apply some of the attitudes and practices of project engineering to the carrying out of particular kinds of archaeological contract projects. He has stressed the management aspects of this project engineering framework, as has Roberts (1978), but rather differently than we have at the Cultural Resource Institute (CRI), Texas Tech University (A7exander 1977; Portnoy 1978; Fox and A7exander 1978; Mayer-0akes and Portnoy 1978). While Fitting and Roberts, each from 
quite different backgrounds, have essentially moved to adapt project engineering methods to the needs of archaeology, we (cf. especially Mayer-0akes 1978b,c) have tried to clarify and "operationalize" contemporary scholarship in archaeology in this new contract context (Mayer-oakes 1978d). Although the future course of events is difficult to foresee, I venture to predict that any further development of the potential schism in the profession (between contract and noncontract kinds of archaeology) will have an important relationship to the way this difference in approach develops.

Since June of 1976, we at Texas Tech University have had the opportunity to explore this new field from the inside, so to speak. With the establishment of a Cultural Resources Institute, we have been quite active in seeking, obtaining and carrying out contract projects in archaeology. In the section that follows we present some of the results of this experience which we feel probably represent a typical reaction. They may be used as a case study in the "introduction to businesslike archaeology" that many academic archaeologists have been involved in for the last four or five years.

\section{The CRI Experience}

In our first 18 months we have covered a significant range of the kinds of contracts that are currently being offered to archaeologists. We have prepared 22 proposals to 13 different sponsoring agencies, all but five being federal government activities. We have been awarded 14 contracts from the following agencies: Belco Petroleum Co.; Bureau of Land Management; Corps of Engineers; Espey, Huston and Associates: Interagency Archeological Services - Denver; Interagency Archeological Services - Washington; National Park Service - Chaco Center; City of Odessa, Texas; Texas Archeological Foundation; Texas Archeological Society; and Texas Tech University. Our applied projects have included major mitigation excavation, two major 100\% inventory surveys, a regional overview literature search, a minor inventory and mitigation plan, a well-pad clearance survey, a field school, a workshop and a publication project. Our financed activities have included a pure research project and two basic research projects. Our contracts have been fixed price, cost-reimbursable (i.e., not fixed price), cash advance research, a subcontract with an academic prime contractor and a subcontract with a corporate prime contractor. We have disagreed with agency archaeologists in proposal evaluation and in report evaluation. We have completed contracts to the satisfaction of all involved.

\section{Basic Research Implications}

While doing this, we have taken some time to try to assess the whole process, and we have been aware that the development of contract work in archaeology has some obvious parallels in the development of other scientific fields, particularly those concerned with environmental matters. My major concern in this paper is to focus more clearly on the topic of basic research in archaeology and on the nature of the scientific community and the relationship of archaeology to this community. I do this quite consciously with a perspective that sees the archaeology of 1978 as irreversibly different from the archaeology of the past; the changed conditions and changed nature of archaeology are, I think, realized and accepted by only a few archaeologists at the present time. I am 
confident this attitude will change. I have this major concern because I feel it is in the best interests of the discipline of archaeology that we (1) clarify our research interests in order to more effectively adapt to the changed conditions and (2) more clearly and closely identify outselves and archaeology with the rest of the broad scientific community.

\section{The New Contract Process}

To most effectively highlight the changed conditions and nature of archaeology, I think a focus of attention on the "new" contract process will be useful. In a major review of the concepts of research design that we have developed (MayerOakes 1978b), I have detailed the historical and other background which leads to the conclusion that contracts these days, in archaeology, are drastically different from contracts associated with the salvage or public era of contract archaeology. The contracts characteristic of the current era of cultural resource archaeology are both more variable and more demanding. We will focus our attention on the detailed nature of this new "contract process" at a forthcoming Interagency Archeological Services (IAS) sponsored workshop.. In this paper I wish to utilize only the stylistic typology of contracts as an example of the range of change in contemporary archaeology.

Table 1. Current Contract Types

TYPE DESCRIPTION

TYPICAL AGENCY

A. Competitive, professional services

B. Non-competitive, professional services

C. Competitive, technical services

D. Competitive bid

Interagency Archeological Department of Defense Bureau of Land Management Soil Conservation Service

None of the four types of contracts listed in Table 1 are like the old-style contracts we associate with the era of salvage archaeology. The salvage and early public era contracts were essentially pieces of paper that directed willing academic archaeologists to go to certain places to carry out their own kind of survey or excavation research. Such contracts were essentialiy noncompetitive and real7y could be considered as "directed research" contracts. This was not labeled "basic research," but some of it was, and most of it was excellent quality research utilized as a training ground for a whole generation of archaeologists. The salvage era archaeologists unknowingly led the way into the future of "research and development" archaeology. This potential for cultural resource management archaeology is currently both unrecognized and unexplored. But this will surely change.

The types shown in Table 1 do not exhaust the possibilities, but do dramatize the major differences currently to be faced in contract work. A primary problem is in the competitive or, alternatively, "sole source" nature of contracts. Almost any kind of project can really be done on a sole source (i.e., noncompetitive) basis, either legally or through subterfuge. The major focus of functional sole source procurement these days appears to be in the various 
approaches to contracting developed through Department of Defense agencies. This is anachronistic because of the fact that types $A$ and $B$ are apparently the preferred types of contract for serious and effective "academic" research interests. The "technical services" type of contract characteristic of BLM needs is only just being recognized and is certainly unappreciated (probably for the wrong reasons) by most of the contracting profession. The final type $D$ contract is highly variable, often providing greatest latitude for academic contractors with access to "hidden cost" support structures, e.g., lowly or non-paid students and amateurs. But it is also the place for "price cutting" and probably the best candidate for producing shoddy archaeology.

\section{Review of Research Types}

In this new and much more complex "real world" of 1978 archaeology I think we need to rethink and redefine ourselves. Our new perspectives must surely include knowledge about and effective reaction to public policy, government bureaucracy, business and profit motives, as well as our own personal role as members of a democratic society. Bevan (1977) has written engagingly of this problem from the larger framework of the U.S. scientific community. His article should be read by all anthropological archaeologists. While Bevan and also Shneour (1977) use the term "basic" research, it appears that the general scientific community has done little to stop and think this matter through since the late 1950s. Surely, the changes in our society, in the world and in science require a more timely set of ideas. We in archaeology have done precious little to contribute to these broad needs.

In reviewing the concept of basic research to see what it means in archaeology I find most support and help in the volume published in 1959 (Wolfle) by the American Association for the Advancement of Science (AAAS) as a result of a symposium on the topic of "Basic Research." Even in such a thoroughgoing event as the symposium obviously was, there is a wide range of opinion expressed about what basic research really is. Alan Waterman (in Wolfle 1959:20) presents the definition used by the National Science Foundation (NSF):

Basic research is that type of research which is directed toward increase of knowledge in science. It is research where the primary aim of the investigator is a fuller knowledge or understanding of the subject under study, rather than a practical application thereof.

In a wider ranging discussion of the topic, Astin defines basic research operationally (in Wolfle 1959:144). "The investigator is thus free, in fact is encouraged, to pursue a line of inquiry to the outer edge of knowledge."

From the point of view of a private research institute, Tuve (in Wolfle 1959: 172) stresses another aspect of basic research.

We $a 11$ know what we mean by truly basic research. We mean a devoted and almost passionate activity in search of new knowledge, not just factual information, but knowledge of the kind which can enlarge our understanding, knowledge which is not isolated facts but related to guiding hypotheses or principles, knowledge which relates to natural law. This kind of truly basic research is a creative activity, an 
expression of wonder and the love of knowledge, and it is correspondingly a highly personal activity. It is concerned with ideas, hopefully and critically directed toward understanding, and it is often the spontaneous effort of one man, or at most of several competent individuals working together. It is not directed or organized, and only in the later stages, often close to technology or to medical use, does it lead to the employment of large groups of specialists operated as a team. By contrast, then, it is the support of ideas by the support of the individual research man who has ideas.

While I am as untutored as any other academic archaeologist in the possibilities for serious analogies with the current state of science in general, I can see, on the basis of my own experience in archaeology since my first professional field work in 1947, that we really need to review where we stand and where we should go. We are now, by virtue of contract archaeology (cf. my editorial letter, Mayer-Oakes 1978a) in a position to take a place among the community of sciences that receive substantial public support for "practical" purposes. This imposes new obligations on us and I, for one, will not simply retreat into academic seclusion. If for no other reason than economic selfinterest, I am very concerned about who is spending my tax dollars on my cultural resources and just. how well they are doing $i t$. And calling it archaeology, my discipline!

As a target for others so concerned, I present below my first stage effort to organize my thinking about different kinds of archaeology in the 1978 context. I see that the terms "pure," "basic" and "applied" can have some real potential for helping us to cope with, manage and perhaps get ahead of the fast-running tide of archaeology in the public interest, under contract, for cultural resource management purposes. Acceptance of the conservation ethic (Lipe 1974) and the personal economic interests of citizenship require no less of every archaeologist!

Table 2. Kinds of Archaeological Research

\begin{tabular}{|c|c|c|}
\hline KIND & $\begin{array}{l}\text { IMPETUS OF } \\
\text { RESEARCHER }\end{array}$ & $\begin{array}{l}\text { NATURE OF } \\
\text { RESEARCH }\end{array}$ \\
\hline
\end{tabular}

\begin{tabular}{lll}
\hline Pure Self-directed & $\begin{array}{l}\text { Fundamental, no clear end } \\
\text { beyond "knowledge." }\end{array}$
\end{tabular}

Basic

Self-directed or Other-directed

Applied Other-directed

Research \& Other-directed Development*
Fundamenta 1 , but with known or anticipated ends in view.

Limited and special purpose. Ends defined at start of research.

Limited and special purpose, including Basic research; aimed at specific end result.
Problem or for ultimate Resource ends

Resource or Client

Problem, Resource or Client

*A special kind of Applied. 


\section{A Potential Problem}

As academic archaeologists have reacted to the opportunities to do archaeology under federal contracts since 1974, a number of problems have developed. While careful exploration of this is beyond the scope of this paper, it is clear that on the basis of this contract experience, with its excessively high component of frustration and hectic, often chaotic, competitive activity, a number of good archaeologists are already retiring from the "fray." To the extent that good quality and experienced minds are thus left outside the rapidly developing contract archaeology field, this field will probably suffer. Specific steps need to be taken to effectively counter this phenomenon. The phenomenon has been called "burn out" and is comparable to a number of other similar reactions to extremely stressful work or life situations. I see this problem as important for the health of archaeology in general. It is also specifically pertinent to the ever-present problems of the potential schism between the contract and research, or business and academic archaeology poles.

\section{Summary and Conclusions}

Anthropology is increasingly playing a part, as an applied science, in American life. So is archaeology, by means of the new context for contract archaeology. This new contract archaeology field is not only a business application of a traditional field of scholarship; it has created the newest and most active frontier for development of the discipline. Here it contrasts with the conservative or traditional area of academic archaeology. The 1978 context for understanding and reacting to archaeology is illuminated by the concepts of problem, resource and client orientation. The new field of distinctive kinds of contract archaeology can make sense if we use this triad of concepts as a perspective, but in so doing we must transform traditional academic archaeology into a new phenomenon--a field of science and scholarship that includes practical application with all its attendant problems. We archaeologists must now join the real world that exists within and around academia, just as the physicists, chemists, biologists, geologists and architects have had to do before us. Perhaps the point made by Les Davis (1978) in this symposium about the need for archaeological engineers is the most significant and truly revolutionary new idea to come out of our realization of the changed conditions for archaeology. If so, the kind of archaeology being done in A.D. 2003 may be very much akin in richness, variety and complexity to the kind of biology or physics being done in 1978.

It is clear to the writer that there is continuing need for at least the four kinds of archaeological research indicated in Table 2. A primary concern for our field (and for other fields of science) is to recognize and continually strengthen the proportionally dwindling "pure" and "basic" categories of research. Vigorous personal action on the part of each and every professional archaeologist is required for the continued heal thy growth and development of archaeology. 


\section{REFERENCES}

Alexander, Jerry

1977 Management in Archeology: Scheduling Techniques Applied to Archeological Projects and Their evaluation. Unpublished M.A. thesis, Department of Anthropology, Texas Tech University, Lubbock.

Astin, Allen V.

1959 Basic Research in Government Laboratories. In: Wolfe, Dael (ed.), Symposium on Basic Research, American Association for the Advancement of Science Publication 56:143-159.

Bevan, William

1977 Science in the Penultimate Age. American Scientist 65(5):538-546. Davis, Hester A.

1976 Applied Archeology: New Approaches, New Directions, New Needs. In: M. V. Angrosino (ed.), Do Applied Anthropologists Apply Anthropology? Southern Antiropological Society, Proceedings 10:77-82.

Davis, Les

1978 Archaeology: Science and Engineering. Paper presented at Symposium at Cibola Anthropological Association (this volume).

Fitting, James E.

1977 Archaeological Management Design. Environmental Management $1(5): 419-423$.

1978a Client Oriented Archaeology: A Comment on Kinsey's Dilemma. Pennsylvania Archaeologist $48(1)$ (in press).

1978b Research as Business. In: The Administration of Anthropological Research, organized by Robert Cunningham (in press).

Fox, Daniet and Jerry Alexander

1978 Business-1ike Archeology. (A PERT analysis applied to archeology). In: "Scholars as Hanagers," report of a 1977 workshop on management techniques in archeology. Interagency Archeological Services, Washington: 44-68.

Kinsey, W. Fred, III

1977 One Archaeologist's Dilernma: A Personal View. Pennsylvania Archaeologist $47(1): 42-44$. 
Lipe, William D.

1974 A Conservation Model for Archaeology. Kiva 39(3-4):213-245. Lipe, W. D. and A. J. Lindsay, Jr., (eds.)

1974 Proceedings of the 1974 Culture Resource Management Conference. Museum of Northern Arizona, Technical Series 14.

Mayer-Oakes, Wiltiam J.

1977 Bureaucrats or Scholars--Who Controls Archeological Scholarships? Paper presented at 1977 Texas Archeological Society annual meeting, Arlington.

1978a On contract work and research in the U.S. Editorial letter in Society for American Archaeology portion of Anthropology Newsletter 19(3): 14 .

1978b Research Design, Multi-stage Operations and the Hierarchy of Archeological Objectives--A Brief Review. Chapter submitted for publication in book on research design, edited by Mark Raab and T. Klinger. Aldine, Chicago.

1978c Back to Basics in Archeological Operations (or, Boas was Right After A11). Paper presented at 14th Annual Symposium, Southwest Federation of Archeological Societies, Carlsbad.

1978d Proposal for a workshop on the contract archeology process. Submitted to Interagency Archeological Services, Washington.

Mayer-Oakes, William J. and Alice W. Portnoy

1978 Research Design and Management Techniques. In: "Scholars as Managers," report of a 1977 workshop on management techniques in archeology. Interagency Archeological Services, Washington: $71-101$.

Portnoy, Alice W. (ed.)

1978 Scholars as Managers. Report of a 1977 workshop on management techniques in archeology. Interagency Archeological Services, Washington.

Roberts, Michae1

1978 Is There a Future for PAST? In: "Scholars as Managers," report of a 1977 workshop on management techniques in archeology: 128140. Interagency Archeological Services, Washington.

Shneour, Elie A.

1977 Science: Too Much Accountabi1ity. Science 195(4282):939. Washington. 
Tuve, Merle A.

1959 Basic Research in Private Research Institutes. In: Wolfle, Dael (ed.), Symposium on Basic Research. American Association for the Advancement of Science Publication 56:169-184.

Waterman, ATan T.

1959 Basic Research in the United States. In: Wolfle, Dael (ed.), Symposium on Basic Research. American Association for the Advancement of Science Publication 56:17-41.

Wolfle, Dael (ed.)

1959 Syrnposium on Basic Research. American Association for the Advancement of Science Publication 56. 


\section{ARCHAEOLOGY, A MATTER OF PUBLIC INTEREST \\ E. Mott Davis}

People are interested in the past. The current Earthwatch catalog, filled with opportunities for laymen to go on scientific expeditions, features archaeological opportunities prominently among the others. Some years ago the editors of the National Geographic found that articles on archaeology attracted more attention than any other kind of article they ran. The Texas State Archeologist's office pays a clipping service to provide it with archaeological items from the Texas press, and these items make up a large packet each month.

Before examining public interest in archaeology, we need to look at our own interest in the question: what difference does public interest make to the professional archaeologist? Why does a symposium on the applied side of archaeology include a paper on public interest in the subject?

I see three primary reasons for our concern. The first reason arises from the nature of our raw data, which comes from the ground. In a 17 our initial investigations, we are dependent upon those who control the use of the land, for it is to them we are indebted for the right to collect our data. Furthermore, they have the responsibility to protect the data from needless destruction. And they are part of the public.

The second reason for our concern is that archaeological funds come largely from legislatures and foundations; in other words, from non-archaeological, non-academic sources; or, in short, from the public.

Third is the matter of misdirected public interest on the part of the collectors and relic hunters who are responsible for much of the destruction of our data. We are very much concerned about their attention to archaeology.

Obviously, then, we are concerned about the public's interest in our work, and it behooves us to understand the forms that such interest takes. I see five such forms: interest in romance, in esthetics, in the nature of the human community, in social roots and in a technical hobby.

\section{The Romantic Interest in Archaeology}

This interest is, in effect, a longing for the past, a past made attractive by being forever beyond our reach. In this mood we can express our yearnings, our fears, our emotional needs, in symbols derived from archaeological information; symbols that we can, if we want, believe to be true. This aspect of lay interest in archaeological information is the soil for the growth of fantasies. Thus Atlantis; thus ancient astronauts; thus Phoenicians sailing to America. There is, of course, little relationship between this kind of interest and the interests of professional archaeologists (even though we surely all have a touch of the romantic in us), and we are obliged to do all we can to keep the public from confusing this kind of interest with what we really mean by archaeology. 
Here we are in the world of the art collector and relic hunter. Their attention focuses on everything from fine La Micoque hand-axes and Folsom points to the works of Phidias and Praxiteles. These people are connoisseurs of artistry and craftsmanship. Herein lies the force behind the commercial trade in antiquities that has become a worldwide scandal, so well reported by Karl Meyer in his book The Plundered Past. We must appreciate, however, that this specimen-orientation, this concentration on form, is what the term "archaeology" actually once meant in the world of learning. It is no surprise, then, that in many minds it still mistakenty characterizes the orientation of the archaeologist. Unfortunately, if we were to depend upon enthusiastic esthetes for our support we would be in difficult circumstances, because their aims represent only a torn fragment of the aims of modern archaeology. The interests of the pure esthete and collector ignore context, and without context we are without meaningful information. Collectors are not archaeologists, and archaeologists are not collectors. We must do all we can to clear up this misconception in the public mind.

The Interest in the Nature of the Human Community

This interest is a concern with archaeological materials as representing the lives of real people--as we ourselves are real people--living in the real past. There is an increasingly widespread public interest in the richness, variety and depth of human experience, a realistic view of the breadth of the situation of humankind. It involves the sober but exciting realization, shared by professionals, that when we uncover archaeological remains we are touching actual past experience, experience whose fragile signs must be treated with respect and skill lest they be lost forever. This is the "human connection," the appreciation of the true subject matter of archaeology. Associated with it is the understanding, discussed by Joel Gunn in this symposium, that archaeological research, as part of paleoecology, contributes to the art of predicting the future of the planet.

This realistic appreciation of archaeology has been increasing markedly during the past fifteen years. Although one still finds ignorance of--and sometimes even hostility toward--archaeological values, it is nevertheless no longer a great surprise to discover a farmer or an engineer or a park superintendent who realizes that archaeological information tells about past behavior, that it is worthwhile for that reason, that it is easily destroyed, and that experience, training and careful work are required to retrieve the information from the ground. Television programs are showing more sophistication. Public officials are actively supporting archaeology; where funds were not available before, they are now forthcoming from legislatures and universities. Furthermore, these officials are often demanding that publicly supported archaeological work be rigorously carried out and adequately reported. Legislation for the conservation of antiquities is enforced now as it was not in the past. We still have far to go, and the situation could turn for the worse; but the changes for the better are clear. Realistic public interest is steadily increasing. 
This is a concern with archaeological information as a basis for fostering local, ethnic and national pride--a means toward social self-realization." This interest supports what James fitting has called both problem-oriented and resource-oriented archaeology, as they are discussed by William MayerOakes in this symposium, and client-oriented archaeology will surely be entering this picture as well. One can see this kind of interest in many Third World countries, where archaeology is encouraged as a help in the struggle for freedom from the psychological heritage of colonialism. In Africa, for instance, archaeological research is changing the situation of former days, when the people were regarded by their European rulers as having no past worth knowing.

Since this kind of interest may or may not correspond to the aims of scientific archaeology, there are times when an archaeologist might be subjected to contradictory pressures. There might be an advance hope that the archaeologist will prove, for instance, that ancient Israelites were in the Palestine area at a given time, that a Spanish mission was located at a specified spot in east Texas, or that the ruins of Zimbabwe were built by Arabs. Fortunately, however, the desire to extend the knowledge of one's own people into the past is usuaily more supportive of research into whatever that past may have been-and this includes most of the work in Israel, Texas and southern Africa. Historic sites archaeology in the United States, the reconstruction of the glories of Teotihuacan and Tikal, and eastern Mediterranean archaeology as a key to the origins of Western civilization, are further examples of archaeological research into social roots that is obliged to come up with meaningful results if it is to continue receiving support.

\section{The Interest in Archaeology as a Technical Hobby}

Just as archaeological work can aid in social self-realization, so can it be a road to individual self-realization. A few members of the public pursue archaeology as a serious technical hobby. They expand and enrich their lives by mastering archaeology as a skilled avocation and carrying on research in collaboration with professionals. These people provide the backbone for state and local archaeological societies. They can point with pride to the fact that some of the greatest archaeological pioneers--Schliemann and Pitt-Rivers, for example--were amateurs. They share with professionals the task of arousing public interest in scientific archaeology. They are often in a position to contribute special skills and knowledge to the field, as illustrated by Les Davis's paper in the present symposium. The rise of certification programs for amateur archaeologists in some states marks the belated recognition by the profession of this smal1 but very important segment of the interested public.

\section{Conclusion}

In summary, then, public interest in archaeology is vital to archaeological research. It can be seen as taking five principal forms: romantic interest, esthetic interest, interest in the nature of the human community, interest in 
social roots and interest in archaeology as a technical avocation. The first two forms of interest are not often of benefit to archaeology; more often they are of harm. Our support comes from the last three, and especially from the interest in the nature of humankind. One of the primary keys to the continuation and expansion of scientific archaeology lies in the currently expanding public interest in the true story of the past, as contrasted with romantic and esthetic interests. This expansion of interest is not taking place automatically, in response to some cosmic law of cultural development. Archaeologists, if they are convinced that their studies are worthy of continuing support, must take an active part in fostering this realistic interest among their fellow citizens. 


\section{ARCHAEOLOGY AND TROUBLED TIMES: \\ CULTURES ASTRIDE SHIFTING CLIMATES AND SLIDING RESOURCES}

Joel Gunn

\section{Introduction}

Archaeologists normally justify their existence in terms of the tax-paying public's interest in the past. While many archaeologists deny that there are any practical benefits from archaeological research, I have always believed that accurate knowledge of the human past contributes to a realistic assessment of ourselves and our potentials. Prehistory, then, is a contributor to that general background of knowledge about ourselves through which we can cope with the problems of designing society and environment to benefit us. In other words, it is basic research and long term benefits can be expected from it.

Two recent developments suggest that archaeologists, if they are inclined, may be in a position to make direct and immediately beneficial contributions toward the solution of modern cultural problems. The first is the energy crisis. Numerous changes in the prehistoric cultures can be interpreted as energy crises and cultural solutions to those crises. The second is the possibility of dramatic climate changes leading to crises in cultural adaptations of all of the modern nations. Since both energy crises and climatic crises result in the same problem, a change in energy resources available to a culture, they can be studied as a class of problems.

This paper is directly concerned with the problem of climatic change. The 20th century has been a period of unusually warm climate (National Academy of Sciences 1975, Bryson and Murray 1977). Under these moderate and biological1y encouraging conditions, 20 th century world culture has flourished, apparently under the assumption that, with minor exceptions, climate is a benevolent constant. Within the context of reliable climate, culture and technology can develop progressively more complex forms, presumably forever, or until the limit of the world's productivity is reached.

Progressively more severe winters since about 1973 appear to be changing the popular theory of climate from one of reliability to one of unreliability. At some point in the future, hopefully soon, the problem of the pattern and effect of these changes will be seriously addressed. Because archaeologists control long paleoclimatic and cultural records, they should be in as good a position as anyone in the scientific community to provide answers to such questions.

Historically, archaeologists have suffered from an identity problem which apparently originated from the time Franz Boas succeeded in making evolution an unpopular topic in anthropology. Without an accepted evolutionary or developmental basis, archaeological theorizing was essentially impossible at any serious level (Willey and Sabloff 1974). However, mental archaeology once again became possible with the reviving of evolutionary theory in the 1950s. By the 1970s authors such as Plog (1974) and Fritz (1973) were asking what contribution archaeologists had to make to the social sciences as a whole. The consensus seemed to be that archaeologists can offer solutions to problems of 
long term culture change as represented in the prehistoric record. Thus the opportunity presented by present circumstances does not require a change of orientation on the part of archaeologists so much as it reflects a changing public theory of culture and climate.

A study by Wendland and Bryson (1974) suggests that the dangers of climatic change are indeed formidable. All of the C-14 dates on past cultures were plotted on a time chart along with periods of known climatic change. The results of this study showed that the beginnings and terminations of most cultures were associated with climatic changes. Furthermore, evidence is presented suggesting that change mechanisms function so that most climatic periods are relatively long and stable and that transitions between climatic periods are brief and abrupt.

If archaeologists are to serve any purpose in a climatic change crisis they have to do two things. First, they must construct models of climatic change which can be tested against the paleoclimatic record. Of course, sensitive and reliable paleoclimatic indicators have to be developed to facilitate testing. This problem does not seem insurmountable in the light of the vast array of chemical and atomic technologies available to scientists today. The situation does, however, suggest that archaeologists are much too slow about developing new, efficient, paleoclimatic measures which are indigenous to their region of study. There is too much reliance on techniques like pollen analysis which is effective only under ideal preservation conditions.

The second important effort is in the direction of models of cultural response to climatic change. Tests of those models should be designed to show whether any cultures have ever successfullily adapted to climatic changes and what were the processes involved. Further, models are needed which do not stem from empirical, past realities but which offer potential avenues of adapation beyond those normally attempted or imagined.

Models of Climatic Change

An example of this avenue of thinking is the following discussion of research being conducted in central and south Texas by the author and several colleagues associated with the Center for Archaeological Research, The University of Texas at San Antonio. First, relative to models of climatic change, one would expect that with all of the money being spent on climate studies by the U.S. government, the United Nations and many other organizations, regional models of climatic change would be available. However, this does not seem to be the case. Most of the work done to date is directed at global climatic models and they are too generalized to apply accurately to local situations. The first task toward understanding local climatic change, then, was to develop a model which shows how local climate, in this case that of Texas, responds to global climatic change. This was done in a rudimentary form last year (Gunn and Mahula 1977) and is currentiy in the process of being expanded to more accurately reflect the processes involved. In its developed form, the model will account for the effect of the various precipitation patterns across the state (Carr 1966) as they are governed by the movements of the jet stream under various global climatic conditions. 
During the process of testing this model using U.S. Weather Service data since 1940, results were produced which immediately appealed to 1ocal businessmen. The analysis suggests that if the present downward trend in global temperatures continues, air conditioning construction and utility costs in office buildings and factories should go down. This information has been used by the San Antonio Economic Development Foundation to lure new business into the region.

In the future we plan to project those and other costs on a quantitative basis and also to determine the effect of climatic change on agriculture and ranching. In cooperation with the Texas Natural Resources Information System, a project is planned using LANDSAT satellite information to monitor climatic change influence on vegetation over the years. Also, we have been provided with funds by the Ewing Halsell Foundation of San Antonio to study weather data in greater detail and over a broader area. The Foundation Director is particularly interested in the effect climatic change has on south Texas ranching. It seems possible, according to some scientists (Mitchel1 1977), that our climatic future may be even more complicated than gradual cooling. If humans continue to use energy in such a way that heat is continually released into the atmosphere, then the natural cooling trend may be reversed, resulting in unusually high temperatures. The consequences would certainiy require drastic response on the part of human cultures.

Working back the other way for a moment, perhaps some will question the usefulness of these exercises to archaeology, which is to say, "Is it practical for archaeology?" I have found, however, that describing the modern effects of climate has helped to conceptualize past effects even on radicaliy different subsistence systems.

Models of Cultural Adaptation

Models of cultural adaptation to climatic crises are unknown to me although there may be some applications of catastrophe theory to be made here (Renfrew 1978, Zeeman 1976). Observations on the archaeology of central and south Texas suggest that native Americans relied more heavily on the area during periods when global climate was cooler and local climate presumably wetter. This is inferred from the fact that sites are intensively occupied during the Middle Archaic and Late Prehistoric, which correlate with colder global temperatures. Both our climatic model and the prehistoric record, then, indicate that if the climate deteriorated, south Texas could be relied on for a larger share of our national subsistence. All of our research, however, has shown that south Texas is climatically unreliable and any investments made in the area would have to be made with some sophisticated ability to deal with patterns in the precipitation regime. Two models come to mind. The first is posited around the Law of the Minimum which is an idea that one should not rely any more on an area than it can support in the worst year. This was probabiy the rule followed by prehistoric populations. Modern implementation of this strategy would require no more than keeping track of previous years and adjusting one's subsistence strategy, probably what crops to plant, to the normal, lowest precipitation. 
Another possible strategy is to try to predict the characteristics of a year and adjust crops and livestock accordingly. Whether reliable predictions can be made remains to be seen. Many climatically influential variables can now be controlled which might make such predictions possible. For instance, sunspot activity is known to influence the global weather pattern (Eddy 1977). Perhaps predictions could be made for a year based on the cycle of sunspot activities.

\section{Conclusion}

Without being overly confident, I would say that archaeologists are in as good a position as anyone to materially assist economic planners and other policy decision makers in a crisis oriented, cultural adaptation situation. Doing so is largely a matter of selecting relevant topics to specialize in and being willing to listen to the needs of businessmen, farmers and ranchers when it comes time to apply those specialties.

\section{REFERENCES}

Bryson, Reid A. and Thomas J. Murray

1977 Climates of Hunger. The University of Wisconsin Press, Madison.

Carr, John T., Jr.

1966 A Climatological Look at Texas. Manuscript on file, Library, Texas Water Development Board, Austin, Texas.

Eddy, John A.

1977 The Case of the Missing Sunspots. Scientific American $236(5): 80-92$.

Fritz, John M.

1973 Relevance, Archaeology and Subsistence Theory. In: C. Redman (ed.), Research and Theory in Current Archaeology:59-82, Wiley, New York.

Gunn, Joel and Royce Mahula

1977 Hop Hill: Culture and Climatic Change in Central Texas. Center for Archaeological Research, The University of Texas at San Antonio, Special Report 5.

Mitchel1, J. Murray, Jr.

1977 Carbon Dioxide and Future Climate. Environmental Data Service. March. 
National Academy of Sciences

1975 Understanding Climatic Change: A Program for Action. Washington, D.C.

Plog, Fred T.

1974 The Study of Prehistoric Change. Academic Press, New York. Renfrew, Colin (ed.)

1978 Trajectory Discontinuity and Morphogenesis: The Implications of Catastrophe Theory for Archaeology. In: Thansformations: Mathematical Approaches to Culture Change. Academic Press (in press).

Wendland, Wayne M. and Reid A. Bryson

1974 Dating Climatic Episodes of the Holocene. Quaternary Research $4(1): 9-24$.

Willey, Gordon R. and Jeremy A. Sabloff

1974 A History of American Archaeology. W. H. Freeman and Company, San Francisco.

Zeeman, E. C.

1976 Catastrophe Theory. Scientific American 234(4):65-83. 


\title{
IV. ARCHAEOLOGY: SCIENCE AND ENGINEERING
}

\author{
Les Davis
}

\section{Introduction}

I shall not presume to advise professional archaeologists on their role as scientists. What I can do is offer some observations I have made over a span of 20 years. These past 20 years have been a time of great change in the emphas is of archaeology in general, and field archaeology in particular. As an aerospace engineer, and occasionally an engineering manager, I have noted the engineering and managerial aspects of field archaeology with more than casual interest.

The archaeologist-manager is haltingly, painfully changing his role. Formerly, in the best of scientific procedure, the archaeologist would maintain a tight control on every item and aspect of his field project. After years of site work and further years of manuscript preparation, the archaeologist would then publish his magnum opus. This publication would present ordered data in support of the conclusions and an exhaustive presentation of the data-recovery methods and techniques.

The archaeologist-manager of today is cast in the role of "Principal Investigator," negotiating contracts for pressure-cooker archaeology and managing a team of specialists, field directors and foremen. The data gathering and the publication are tightly scheduled as part of the contract. Control and direction of data-gathering techniques is still maintained in detail.

Engineering of field work is usually based on experience, some undergraduate review courses and handyman "know-how." Every field archaeologist usually has thorough knowledge and skill in the use of chains, transits and plane tables. There are isolated innovators who attempt to introduce new technical equipment and materials into field work.

I submit that the present fund of archaeological expertise is in short supply and that the use of trained, skilled and motivated archaeologists in the performance of many of these tasks is wasteful and sometimes counter-productive. The detailed descriptions of data gathering are published by the archaeologist because there are no accepted standard methods to reference. The tight control of field techniques is implemented for the same reason, although there are some specific survey techniques gaining wide acceptance.

\section{Archaeological Engineering}

There are three steps that can be taken to release the archaeologist from the tedium of detail, maximize the return on his scientific training and improve the efficiency and safety of field operation. The recommendations are broad generalizations with specific examples and are intended as a point of departure on the subject.

First, many of the present practices need to be quantized. Among these are troweling, arbitrary levels, survey patterns, precision versus accuracy in 
measurements, use of compass, plane table and theodolite (transit), screening, shoveling, etc. The quantization process could include a literature search, field observation and controlled experiments. There is a great need for operational analyses to be made on the standard archaeological field tasks. These include travel to and from base camp, logistics, excavations, surveys, field laboratory location and tasks, etc. In order to obtain maximum output with minimum cost, the intuitive approach to field task organization is no longer sufficient. Recent theoretical studies have shown that it is possible to increase the time for completion of a total task by decreasing the time of certain individual tasks (Graham 1978).

Secondly, the results of the above quantizations, as well as standard geometric, mathematical and other data, should be incorporated in a field archaeology handbook. The handbook could serve as a standard reference for contract proposals, report writing and peer review. I do not mean to imply the handbook is to be slavishly adhered to, but instead that it be used as a standard base to depart from. I foresee statements such as, "The survey search pattern used was pattern five from the Field Archaeology Handbook, modified to use 30-meter spacing between tracks." Other uses for the handbook would be as a source of useful half-remembered facts, such as number of acres in a square mile, trigonometric identities, etc., as an aid in planning archaeological work and as a generally useful training aid (some of these kids of data are found in the appendices of the field guide published by Hester, Heizer and Graham 1975).

Finally, and I think most important7y, the burden of much of the technical nonarchaeological work should be lifted from the shoulders of the archaeologist and assigned to a technician. We can give this person any of several titles:

Engineer, Technologist, Para-archaeologist, Technical Aide. A full-time "superhandyman" is envisioned with background education in civil engineering, soil mechanics, electrical power, mechanics (physics) and some archaeology review courses. A full-time engineer would keep abreast of the latest developments in techniques and materials.

\section{Conclusion}

In closing, I wish to touch on a sensitive subject. You may well say, "Davis wishes to isolate the scientist from direct data gathering." My reply to that is, I do not. I wish to enable the scientist to maintain control of method and technique, but I also wish to furnish a base from which he can rationalize his departures from established, quantized, documented procedures. It has been my sad experience in engineering that some scientists are prone to biasing, perhaps unconsciously, the data to favor their conception of what the data should be. I have known scientists who could draw a smooth curve through flyspecks on a windowpane.

I further wish to free the archaeologists on a field site, from undergraduates through scientists, from wasting their valuable training and experience on nonproductive tasks. 


\section{REFERENCES}

Graham, Ronald R.

1978 "The Combinatorial Mathematics of Scheduling." Scientific American 238(3):124-132.

Hester, T. R., R. F. Heizer and S. A. Graham

1975 Field Methods in Archaeology. 6th edition. Palo Alto. 


\section{RESOURCE MANAGEMENT: THE FUTURE OF THE PAST \\ A7ton K. Briggs}

\section{Introduction}

A culture's selective remembrance of the past is a fundamental component of its long-term maintenance. This remembrance is expressed by consciously developing and utilizing elements of the cultural record, which can include archaeology, anthropology, architecture, and oral and written histories. The development and utilization of these cultural elements by individuals and groups results in cultural resources which should be integrated as a whole to provide a reflection of human use of natural and human resources through time. Present usage of the resources of the past with regard for future needs is the concept which guides cultural resources management. The concept may be germinal in all cultures, innately followed by most, consciously articulated by some. In this culture (country) and increasingly elsewhere, it is meted out in local, state and federal policies, guided by regulations, protected by law.

\section{The Problem: Dwindling Archaeological Resources}

Perhaps the most underdeveloped of cultural resources is the archaeological record. While this country has a relative abundance of prehistoric resources-the result of the more than 15,000 years of human usage of varied environments vis-à-vis the historic period--their continuing susceptibility to degradation as a result of natural and human processes has not been conducive to their preservation. Natural processes have been the most destructive of agents affecting prehistoric resources until the recent past, when man's ability to disturb earth surfaces outstripped that of nature.

Present needs for commodities and convenience have transformed global and galactic engineering into a reality and, as such, affect all cultural resources, but with emphasis again on the archaeological record. While the losses of the archaeological record as a result of urban development in the area of Houston are different from those in the lignite deposits of northeast Texas, as those in the uranium mines of southern Texas are from those on the outer continental shelf of the Gulf of Mexico, these losses are interrelated in our quest to provide energy. The more successful we are in meeting our energy needs, the more significant and cumulative the impact on prehistoric and other cultural resources will be. One function of cultural resource management is the reconciliation of these impacts with a need for cultural conservation and continuity. Public awareness of the value and significance of cultural resources and the need for their conservation has brought about the creation of laws, agencies and attendant programs whose functions maximize cultural resources.

\section{First Step Solution: Public Law}

The law enacted to protect federal antiquities in the early part of this century is both questioned and supported in the courts today. Despite the lack of clarity regarding the "organic" legislation, support of preservation law continues to the present. As each law passed established new inroads for further 
legislation, all are important. Perhaps the most comprehensive of these laws is the National Historic Preservation Act of 1966, which establishes a national policy with assigned responsibilities, procedures and regulations for protecting the cultural and historic environment. The National Environmental Policy Act of 1969 further enhances this policy. President Nixon's Executive Order 11593 of May 13, 1971, directs federal agencies, in cooperation with the Tiaison officer for historic preservation for the state or territory involved (State Historic Preservation Officer), to locate, inventory and nominate all cultural resources under their jurisdiction and control which appear eligible for the National Register of Historic Places. Until the inventories and evaluations are completed, any federally owned property which might qualify must be protected. The Archeological and Historic Preservation Act of 1974 represents another step toward assigning responsibility and providing funds for cultural resource management. Essentialiy, the Act provides up to one percentum of authorized project funds to be utilized for the investigation of significant cultural resources affected by the project. Arguments over what level of investigation is appropriate (survey or mitigation) and what constitutes one percentum continue, but upon clarification, the law should function to preserve not only important elements in archaeology but other cultural resources as well.

Agencies once responsible for marking historic places, administering parks, recreation and wildlife areas or building highways, reservoirs and airports now find themselves in the business of protecting and preserving elements of the past. While some agencies articulate preservation as a policy and provide procedures for protection, others exploit sites for recreation and cultural enrichment. Land-modifying agencies now mitigate the loss of sites by the application of ameliorative procedures--survey, scientifically-oriented recovery, analysis, publication and curation--to save the significant features prior to the effect resulting from the undertaking.

The varied perspectives of changing agency programs involving cultural resources require a we11-funded federal agency to correlate a national managernent program. The outgrowth of the Bureau of Outdoor Recreation and the successor to it, the newly created Heritage Conservation and Recreation Service, wi11 be the focal point for actions related to the cultural, natural and recreational resources of the nation. In general, the Heritage Conservation and Recreation Service will not be a land-managing agency but will discover, protect and integrate management of resources. This translates to programs which (a) identify, classify, establish and maintain registers for heritage resources, (b) formulate policies and programs for their preservation and (c) coordinate federal, state and local policies and actions. Such an important task and long-lived responsibility will involve federal, state and local governments, directly and indirectly supported by the private sector. The strength and success of the concept will depend on ever-increasing direct support by individuals, organizations, business and industry.

\section{Second Step Solution: A Conservation Ethic}

To retain the support of groups and individuals, those directly involved in resource management must determine the most efficient ways to use a dwindiing resource. Foremost in importance is the adoption of the conservation ethic. Next is the responsibility to protect significant cultural resources while attempting to locate and assess the importance of those cultural resources yet unknown. Third is the need to address the present state or condition of the 
cultural resource and the impact, known and cumulative, that is occurring and is likely to continue. Finally, we must attempt to balance the sample of cultural resources lost and saved.

Adopting a conservation ethic is critical to the long-term existence of cultural resources. Archaeological sites are frequently recovered because they are considered significant in prehistory; this concept of significance is in large part determined by the current state-of-the-art. Archaeological sites not now recommended for investigation may be highly significant in the future. Tomorrow's techniques will be more highly refined and more effective and efficient; many sites under investigation today merit subsequent and repeated inquiry. The conservation ethic provides data and, properly practiced, a cultural resource; inherent within the concept is a provision for multipie-resource utilization and more interdisciplinary study. Fundamentally, however, the concept is consistent with the task of managing a vague, but finite, holding.

While protecting the known cultural resources, continuing efforts should be underway to gather information concerning as yet unrecorded resources. Natural area surveys, urban planning surveys, project-related surveys, amateur reports, discoveries--all have their place here, each highly significant. Each site of similar significance adds a slight amount of flexibility to a management program; each "unique" archaeological site strengthens management approaches. Each site added to the inventory of cultural resources adds to the pool of information on humans and the past and broadens the perspectives of cultural resource management by providing a larger sample of resources to use.

Specific resources are often exploited to the detriment of other resources. The effort made to preserve cultural resources is consistent with other forms of conservation. As we are efficient at saving water, land and energy, so must we be efficient at saving cultural resources. Planning growth and consumption of resources is a solution to inadvertent loss and, as such, planning provides a remedy for cultural resources management. By examining the current state of cultural resources, where they occur, their context and condition, we can predict with relative surety their likelihood in other areas yet unaffected by impending development. Development can be charted in a similar fashion. The correlation of these and other factors provides useful insights into potential areas of loss and the need for replenishment.

Replenishment of a non-renewable resource is performed by selecting, on the basis of previous loss, identified sites for protection and/or acquisition. Once these sites are selected, information regarding their status must be distributed in such a format as to enable agencies, groups and individuals to consider these sites from the standpoint of their own program activities. These sites must be accorded a special place in the planning process and be protected by law, regulation and policy if they are to retain the character of an appreciated legacy.

\section{Conclusion}

There is certain cultural arrogance at play when we select cultural resources which we believe are representative of our past. While we are not fully conscious of what we have lost or are trying to save, we attempt to preserve those things which have shaped us or which we have transformed. Those resources 
which we have saved will be accepted as part of our environment. Those resources which slipped through our fingers will be examples of our failure and the work for tomorrow's resource managers. Moreover, what is selected now will be the past of the future. 